\title{
Causa infrecuente de trastorno evacuatorio por puente mucoso rectal en una paciente con enfermedad de Crohn
}

\author{
Lucía Secondo, Adrián Canavesi, Alejandra Arriola, Nicolás González \\ Clínica de Gastroenterología "Prof. Dr. Henry Cohen". Hospital de Clinicas. Facultad de Medicina. Montevideo, Uruguay.
}

Acta Gastroenterol Latinoam 2020;50(3):300-302

Recibido: 14/03/2019 / Aceptado: 13/05/2019 / Publicado online: 28/09/2020

\section{Resumen}

Se presenta el caso clínico de una mujer de 48 años, con diagnóstico de enfermedad de Crohn de 28 años de evolución, con trastorno evacuatorio crónico secundario a la presencia de un puente mucoso a nivel de recto bajo. Se realizó tratamiento endoscópico mediante la sección del puente mucoso, sin incidentes, con resolución de los sintomas de manera inmediata.

Palabras claves. Puente mucoso, enfermedad de Crohn, tratamiento endoscópico, trastorno defecatorio.

\section{Infrequent constipation cause due to a mucosal rectum bridge in a patient with Crohn's disease}

\section{Summary}

A case is presented of a 48-year-old patient, with a 28-year history of Crohn's disease, with chronic constipation with outlet obstruction symptoms due to the presence of a mu-

Correspondencia: Lucía Secondo Av Italia, 11600 Montevideo, Departamento de Montevideo (Hospital de Clinicas). Montevideo, Uruguay

Correo electrónico: lucia.secondo@gmail.com cosal bridge at the low rectum. Endoscopic treatment was performed with section of the bridge, without any complications, and with immediate resolution of the symptoms.

Key words. Mucosal bridge, Crohn's disease, endoscopic treatment, defecatory disorder.

\section{Caso clínico}

Mujer de 48 años que presenta enfermedad de Crohn diagnosticada a los 20 años, L2 A2 B2 por clasificación de Montreal, ${ }^{1}$ con múltiples brotes severos que requirieron corticoides e inmunomoduladores.

A once años del diagnóstico se realizó hemicolectomía izquierda con anastomosis colo-cólica termino-terminal por oclusión intestinal secundaria a la actividad inflamatoria de su enfermedad.

Consultó por alteración de su hábito evacuatorio que, si bien movilizaba todos los días, refería tenesmo, esfuerzo defecatorio y debía realizar maniobras digitales. Se interpretó como trastorno evacuatorio crónico tipo obstrucción al tracto de salida. No presentaba otros síntomas digestivos.

$\mathrm{Al}$ tacto rectal, se palpa puente transversal a nivel de recto bajo próximo al canal anal, de consistencia fibroelástica, que divide la luz en dos hemicircunferencias. La mucosa rectal presentaba lesiones polipoideas blandas y móviles.

Se realizó videocolonoscopía, observándose a nivel de recto bajo próximo a canal anal puente mucoso de $10 \mathrm{~mm}$ de grosor que dificultaba el pasaje del endoscopio (Figuras 1 y 2). 
Figura 1. Visualización frontal del puente mucoso

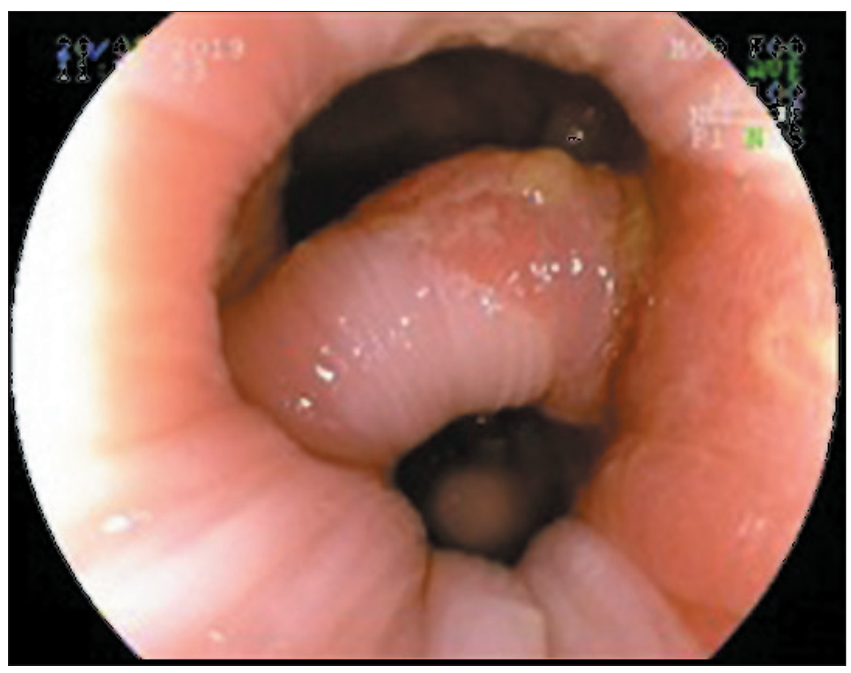

Figura 2. Retroversión en recto bajo con visualización del puente mucoso

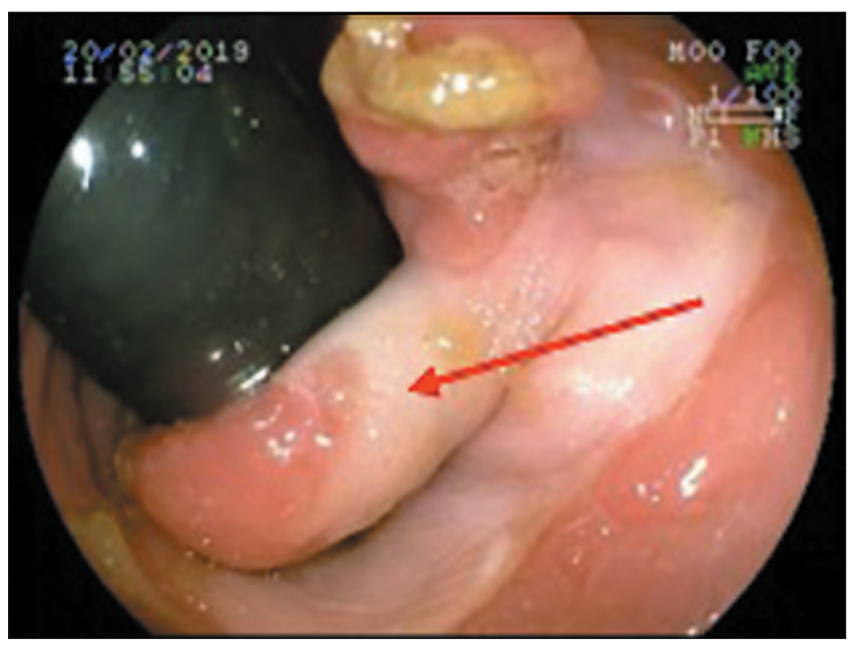

Se discutió con equipo de coloproctología las opciones respecto del abordaje terapéutico, considerando que no existía un beneficio significativo del proctológico sobre el endoscópico, y se optó en conjunto por la vía endoscópica. Se seccionó el puente mucoso con papilotomo de punta (Needle Knife, Boston, Scientifics, Natick, Massachusetts), se utilizó corriente de corte-coagulación con unidad electroquirúrgica ERBE ICC 200 (Efecto 3, 120-60 W), sin incidentes (Figuras 3 y 4). Se consideró la opción de realizar ligaduras laterales previas a la sección del puente mucoso, pero debido a que estos mismos son característicamente muy poco vascularizados, con baja probabilidad de sangrado en agudo y diferido, se optó por utilizar corte únicamente, contando con el instrumental necesario (clips) frente a la eventualidad de sangrado.
Figura 3. Corte con papilotomo de punta

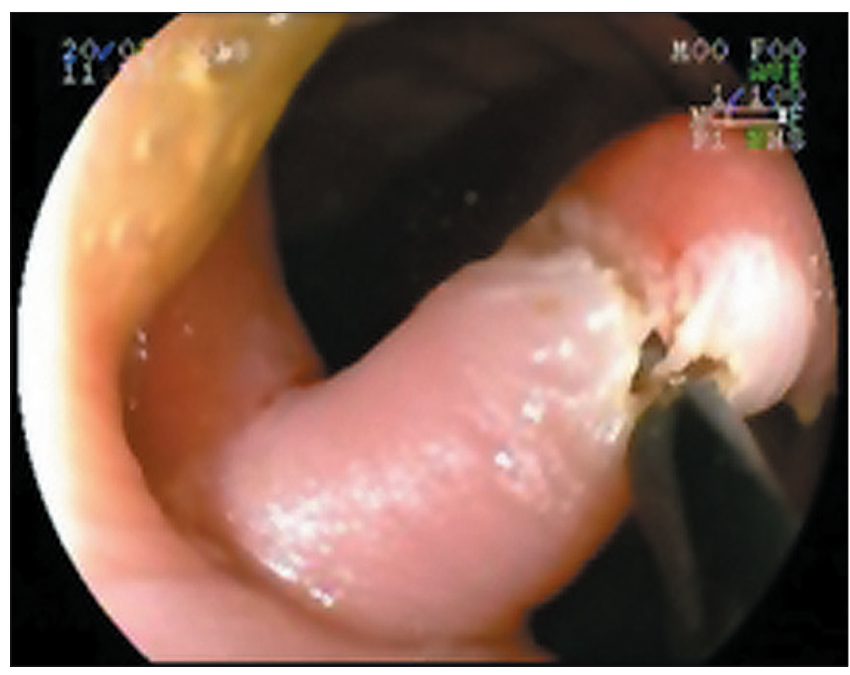

Figura 4. Sección completa de puente mucoso

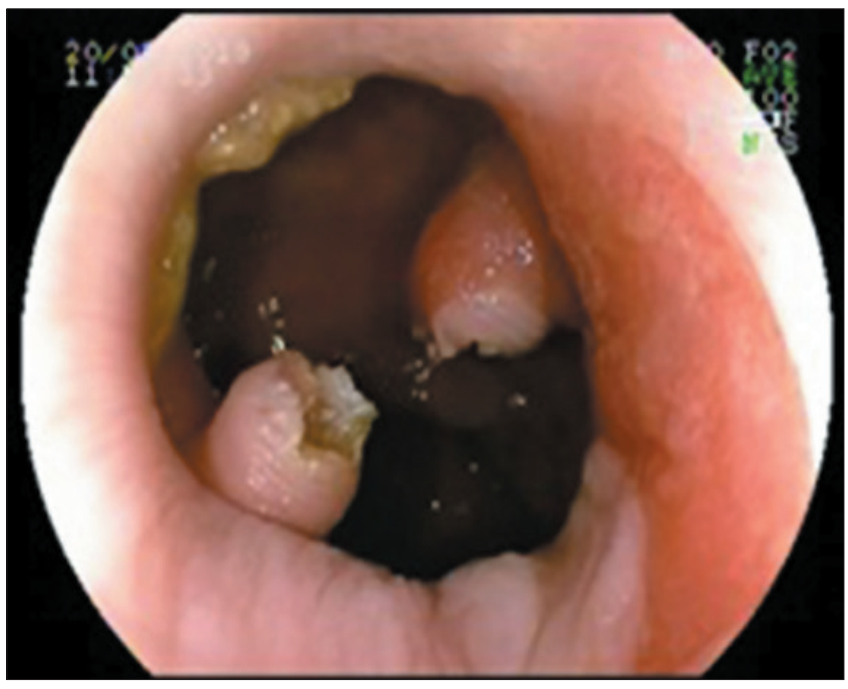

En recto se observaron múltiples pseudopólipos.

Se ingresó a la paciente para observación durante 24 horas, no presentando dolor ni sangrado.

A las 48 horas del procedimiento terapéutico la paciente refirió mejoría de la sintomatología, con deposiciones Bristol 4, sin esfuerzo defecatorio ni necesidad de maniobras digitales.

\section{Discusión}

Se presenta el caso de una paciente con trastorno de la defecación por la presencia de un puente mucoso a nivel de recto bajo.

Los puentes mucosos generalmente están formados por ulceraciones de todo el grosor del epitelio seguido por un proceso regenerativo que deja la mucosa con aspecto 
polipoideo o puentes. Estos se forman en las fases de regeneración y curación de la inflamación. Histológicamente, se caracterizan por hallazgos de inflamación y tejido de granulación. $^{2}$

Los puentes mucosos se ven en pacientes con larga historia de enfermedad inflamatoria intestinal con múltiples brotes, generalmente severos, y su presencia refleja inflamación pasada y no actual, como en el caso de esta paciente. Se corresponden con una lesión de naturaleza benigna, sin potencial neoplásico. ${ }^{2}$

Generalmente, no presentan manifestaciones clínicas, y cuando lo hacen, dependen de su topografía. Cuando se ubican en colon, pueden presentar síntomas oclusivos o de constipación, existiendo algunos reportes en la literatura. ${ }^{3-5}$

Si bien lo más frecuente es que se observen en colitis ulcerosa y enfermedad de Crohn, también pueden observarse en colitis severas por amebiasis, isquemia o disentería bacteriana. ${ }^{2}$ Pueden verse también como consecuencia de anastomosis quirúrgicas, causando síntomas de constipación..$^{3,4}$

También pueden formarse puentes mucosos a nivel de la anastomosis en el pouch en J ileoanal, descrito en la literatura como "síndrome de puente apical". ${ }^{4}$ En el trabajo de Takagi et al., se realizó tratamiento quirúrgico de este tipo de puente por vía transanal con asistencia endoscópica. ${ }^{6}$

En la literatura actual, no hemos encontrado casos reportados de puentes mucosos rectales tratados exclusivamente por vía endoscópica.

\section{Conclusión}

Se presenta una paciente con una causa infrecuente de trastorno de la defecación por un puente mucoso rectal, que se resolvió de manera exitosa por vía endoscópica.

Creemos que debe tenerse en consideración esta etiología como causa de trastorno evacuatorio y considerar la resolución endoscópica como una excelente alternativa terapéutica.

\section{Referencias}

1. Gomollón F, Dignass A, Annese V, Tilg H, Van Assche, Lindsay JO, Peyrin Biroulet L, Cullen GJ, Daperno M, Kucharzik T, Rieder F, Almer S, Armuzzi A, Harbord M, Langhorst J, Sans M, Chowers Y, Fiorino G, Juillerat P, Mantzaris GJ, Rizzello F, Vavricka S, Gionchetti P. 3rd European Evidence-based Consensus on the Diagnosis and Management of Crohn's Disease 2016: Part 1: Diagnosis and Medical Management. Journal of Crohn's and Colitis 2017: 3-25.

2. Itzkowitz SH, Potack J. Pólipos colónicos y síndrome de poliposis. Sleisenguer y Fordtran. Enfermedades Digestivas y Hepáticas "Fisiopatología, Diagnóstico y Tratamiento". 10ma edición. España: Elsevier España, 2017: 2213-2247.

3. Weinstock LB, Shatz BA. Endoscopic treatment of a colonic anastomotic mucosal bridge. GIE 1994; 40: 773-774.

4. Kusunoki M, Okamoto T, Ikeuchi H, Yoshikawa H, Yanagi H, Shoji Y, Yamamura T, Utsunomiya J. Apical Pouch Bridge Syndrome after ileal J Pouch-Anal Anastomosis. Dig Surg 1996; 13: 474-477.

5. Goldberger LE, Neely HR, Stammer JL. Large mucosal bridges: An unusual Roentgenographic Manifestation of Ulcerative Colitis. Gastrointest Radiol 1978; 3: 81-83.

6. Takagi K, Nagata H, Ishizuka M, Sakuraoka Y, Kubota K. Endoscopy-assisted Transanal Division of an Apical Pouch Bridge after Restorative Proctocolectomy with a J-shaped Ileal Pouch. Surg Laparosc Endosc Percutan Tech 2008; 18: 486-488. 